\title{
Article
}

\section{Temperature and Solvent Facilitated Extrusion Based 3D Printing for Pharmaceuticals.}

Dores, Filipa, Kuźmińska, Magda, Soares, Cindy, Bohus, Marton, Shervington, Leroy Alexander, Habashy, Rober, Pereira, Beatriz, Peak, Matthew, Isreb, Abdullah and Alhnan, Mohamed A

Available at http://clok.uclan.ac.uk/33935/

Dores, Filipa, Kuźmińska, Magda, Soares, Cindy, Bohus, Marton, Shervington, Leroy Alexander ORCID: 0000-0003-0663-0583, Habashy, Rober, Pereira, Beatriz, Peak, Matthew, Isreb, Abdullah ORCID: 0000-0001-9939-6161 et al (2020) Temperature and Solvent Facilitated Extrusion Based 3D Printing for Pharmaceuticals. European Journal of Pharmaceutical Sciences, 152 (105430). ISSN 0928-0987

It is advisable to refer to the publisher's version if you intend to cite from the work. http://dx.doi.org/10.1016/j.ejps.2020.105430

For more information about UCLan's research in this area go to http://www.uclan.ac.uk/researchgroups/ and search for <name of research Group>.

For information about Research generally at UCLan please go to http://www.uclan.ac.uk/research/

All outputs in CLoK are protected by Intellectual Property Rights law, including Copyright law. Copyright, IPR and Moral Rights for the works on this site are retained by the individual authors and/or other copyright owners. Terms and conditions for use of this material are defined in the policies page.

\section{CLoK}

Central Lancashire online Knowledge www.clok.uclan.ac.uk

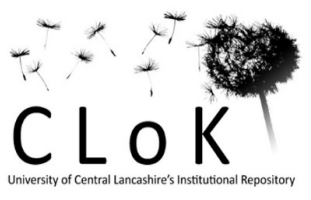


1 Research paper

2 Temperature and Solvent Facilitated Extrusion (TASFEX) Based 3 3D Printing for Pharmaceuticals

4

5

6

7

8

9

10

11

12

19

20

21

22

23
Filipa Dores ${ }^{1}$, Magda Kuźmińska ${ }^{1,2}$, Cindy Soares ${ }^{1}$, Leroy Shiverington ${ }^{1}$, Rober Habashy ${ }^{1}$, Matthew Peak ${ }^{3}$, Abdullah Isreb ${ }^{1}$, Mohamed A Alhnan ${ }^{4 *}$

${ }^{1}$ School of Pharmacy and Biomedical Sciences, University of Central Lancashire, Preston, Lancashire, UK

${ }^{2}$ Faculty of Pharmacy with the Laboratory Medicine Division, Medical University of Warsaw, Warsaw, Poland.

${ }^{3}$ Paediatric Medicines Research Unit, Alder Hey Children's NHS Foundation Trust, Liverpool, UK

${ }^{4}$ Institute of Pharmaceutical Sciences, King's College London, London, UK. 
A B S T R A C T

25

On demand manufacturing of patient-specific oral doses provides significant advantages to patients and healthcare staff. Several 3D printing (3DP) technologies have been proposed as a potential digital alternative to conventional manufacturing of oral tablets. For additive manufacturing approach to be successful for on-demand preparation, a facile process with minimal preparation steps and training requirements is needed. A novel hybrid approach to the 3D printing process is demonstrated here based on combined solvent and heating elements/factors/aspects to facilitate extrusion. The system employed a moderate elevated temperature range of $\left(65-100{ }^{\circ} \mathrm{C}\right)$, a brief drying period, and a simple set-up. In this approach, a compact powder cylinder is used as a pharmaceutical ink to be extruded in a temperaturecontrolled metal syringe. The process proved compatible with hygroscopic polymers [Poly(vinyl alcohol (PVA) and poly(vinyl pyridine) (PVP)] and a number of pharmaceutical fillers (lactose, sorbitol and mannitol). The fabricated tablets demonstrated compendial acceptable weight and content uniformity as well as mechanical resistance. In vitro drug release of theophylline from 3D printed tablets was dependant on the nature of the polymer and its molecular weight. This reported approach offers significant advantages compared to other 3DP technologies: simplification of pre-product, the use of a moderate temperature range, a minimal drying period, and avoiding the use of mechanically complicated direct extruder machinery. In the future, we envisage the use of this low-cost and facile approach to fabricate small batches of bespoke tablets.

Keywords: Direct Ink writing, personalized, patient-specific, small batch, early phase clinical trials 


\section{Introduction}

The demand for personalised therapies has been increasing over the last decade due to the most recent advances in pharmacogenomics and stratified medicine. This has allowed complex diseases and their biological mechanisms to be better understood and to develop more effective strategies to predict and prevent illnesses, as well as to treat them [1-3]. Such developments in personalised therapies induced the interest in developing digital solutions for small batch production of patient-specific dosage forms $[4,5]$.

The past few years have witnessed a growing interest in 3D printing (3DP) as an on-demand manufacturing tool for small batch manufacturing, age-specific products in paediatrics [6,7] and meeting the needs of polypharmacy [8-10]. With several 3DP technologies available, fused deposition modelling (FDM) 3DP has been proposed as a low-cost solution for the fabrication of patient specific dosage forms [11-16]. The FDM technology offers significant potential advantages including process simplicity, the lack of drying or finishing steps and potential of mass production of low-cost pharmaceutical printers and ink cartridges. However, FDM 3DP has to overcome some significant technical challenges to wider uptake and adoption as it exposes the starting pharmaceutical material to two sequential-thermal processes (when hot melt extrusion-based filaments are used as a feed) [5, 17], engineering and optimizing the 'feedability' of the filament [18-20], as well as minimising the risk of mechanical and physical modification of the filament during storage prior to on-demand 3DP. Such challenges might hinder or slow down the advances of this important technology in the pharmaceutical market. Several modifications to FDM 3DP have been applied to reduce the thermal stress of the printing process. For instance, Okwuosa et al. [21] pioneered the use of poly(vinyl alcohol) (PVA) to reduce the printing temperature to as low as $110^{\circ} \mathrm{C}$. Other adaptations have further reduced the printing temperature by employing polymers with low glass transition temperature $\left(90^{\circ} \mathrm{C}\right)$ [22], by the replacement of filaments with softer extruded polymer strands as low as $54{ }^{\circ} \mathrm{C}[23,24]$, or by using water in filament preparation step as a temporary plasticiser [9].

Extrusion-based 3DP has been proposed as an alternative method of manufacture of tablets. While the former obviates the need of engineering and stabilising filaments, it faces a major challenge of extruding a material into solidifying structures in acceptable time. The extrusion of semi-solids (drug suspension) at room temperature can be employed using a printer often used in tissue engineering [10, 25-27]. The process involves the use of powder slurry in a significant amount of water [25, 27, 28] or ethanol [29]. By using thermally heated piston-operated syringe $\left(<70{ }^{\circ} \mathrm{C}\right)$, extrusion-based $3 \mathrm{D}$ printing was also employed to produce solid self-micro-emulsifying drug delivery systems [30] and chewable jelly-like tablets [31]. Alternatively, extrusion can be carried out at high temperature with built-in screw extruder [32]. However, this promising technology must overcome several barriers such balancing efficient extrusion process with the use of typically heavy machinery (hot extruder motor assembly) that are 
often needed to provide sufficient torque for extrusion as well as providing easy solution for batch-tobatch cleaning of complex-shaped screws in the extruder assembly.

In this paper, we present the use of a novel alternative approach of temperature and solvent facilitated extrusion-based 3D printing as a facile manufacturing process suitable for extemporaneous preparations near to the patient. This hybrid approach of combining solvent and elevated temperature for fabrication of oral tablets uses an extrusion-based system that is delivered by simple metal syringe. We envisage the use of a compressed powder cylinder as a pharmaceutical ink.

\section{Materials and methods}

\subsection{Materials}

Theophylline was purchased from Acros Organics (UK). Three grades of Poly(vinyl alcohol) were used: PVA 20-30K and PVA 83K were supplied from Fisher scientific UK, and PVP Parteck ${ }^{\circledR}$ MXP [MXP, k75] was donated by Merck (Darmstadt, Germany). Polyvinylpyrrolidone (PVP, Plasdone ${ }^{\mathrm{TM}}$ K-29/32) was donated by Ashland (UK). Sodium stearyl fumarate (PRUV) was donated by JRS (Germany) and sorbitol was purchased from Merck (Parteck SI, Germany). D-mannitol, lactose and HPLC gradient grade acetonitrile were obtained from Fisher Scientific Ltd (Loughborough, UK).

\subsection{Preparation for the feed}

The model drug (theophylline) and polymer (PVA 20-30K, Parteck [MXP, k75], PVA 83K, PVP) in addition to other additives were accurately weighed and thoroughly mixed via shear mixing using Krups F20342 grinder (Germany). The breakdown of each blend compositions is detailed in Table 1. Initially, sorbitol was selected as a primary plasticiser as established plasticising capacity for PVA matrixes [33, 34] and structure enhancer. Lactose and D-mannitol were added for common use as highly soluble structure enhancers [35, 36]. Preliminary screening work indicated that material flow from the syringe could be significantly enhanced by the addition of sodium stearyl fumarate at $5 \%$ as a lubricant. Further increase in of sodium stearyl fumarate led to incomplete 3D printing due to poor adhesion of the tablet to the printing plate or weak fusion of the printed layers. To approximately $10 \mathrm{~g}$ of each blend, an additional $2 \mathrm{~g}$ of deionised water was added to each formulation and mixed for an additional 30 seconds. Each blend was compressed using a $12 \mathrm{~mm}$ diameter metal syringe (Hyrel 3D, Atlanta, USA) to form $10 \mathrm{~cm}$ height cylinder. The compressed cylinder (based on $12 \mathrm{~g}$ of polymer blend + water) were stored in plastic polybag and used as feed for the 3D printing process (Section 2.3).

In order to assess the impact of the filler nature, sorbitol was replaced with an equivalent amount of Dmannitol or lactose. To assess the impact of different plasticiser concentrations of sorbitol: $15 \%, 20 \%$ and $25 \%(\mathrm{w} / \mathrm{v})$ were assessed. Table 1 provides a summary of all formulations prepared using TASFEX technology. 
114 The tablets were designed in a cylindrical shape using Autodesk ${ }^{\circledR}$ 3ds Max Design 2019 (Autodesk, 115 Inc., USA). The designs were then imported to the Slic3r (version 1.3) software in stereolithographic 116 (STL) format and converted to gcode files using the settings specified as: layer thickness $0.3 \mathrm{~mm}$, first 117 layer thickness $0.5 \mathrm{~mm}$, speed perimeters $50 \%$, infill speed $7 \mathrm{~mm} / \mathrm{sec}$, travel speed $15 \mathrm{~mm} / \mathrm{sec}$, first 118 layer build speed $7 \mathrm{~mm} / \mathrm{sec}$, and nozzle diameter $1.19 \mathrm{~mm}$.

119 A Hyrel System 30M (Hyrel 3D, Atlanta, USA) equipped with a VOL-25 (Volcano) modular head and 120 a 16-gauge stainless steel tip was used to fabricate the tablets. The default glass plate was replaced with 121 an acrylic sheet for better adhesion to the building plate. The settings inserted in the Repetrel software (version 3.0) for the printer head were: nozzle diameter: 1.194, thickness of layer z: $0.3 \mathrm{~mm}$, motor pulses rate: 2.3 pulses/nL, infill percentage: $100 \%$ and a material flow multiplier: 1.2. Following the printing process the tablets were dried for 2 hours at $50{ }^{\circ} \mathrm{C}$ using Binder Drying chamber 9010 (Binder $\mathrm{GmbH}$, Germany). Prior to printing, the compressed cylinder was placed in the heated syringe and heated at processing temperature for $30 \mathrm{~min}$.

\section{7}

128

\subsection{Thermal analysis}

Samples of the raw materials, dry physical mixture and 3D printed tablets were analysed by differential scanning calorimetry (DSC) and thermogravimetric analysis (TGA). DSC Q2000 (TA Instruments, Elstree, UK) was used to assess the thermal behaviour of the samples: approximately $5 \mathrm{mg}$ samples were scanned from 0 to $300^{\circ} \mathrm{C}$ using at a heating rate of $10^{\circ} \mathrm{C} / \mathrm{min}$ and a nitrogen purge of $50 \mathrm{~mL} / \mathrm{min}$ using standard aluminium pans and lids. TGA Q500 (TA Instruments, Elstree, Hertfordshire, UK) was used to analyse approximately $10 \mathrm{mg}$ of each material filled in platinum pans. Samples were heated at a rate of $10^{\circ} \mathrm{C} / \mathrm{min}$ from $25^{\circ} \mathrm{C}$ to $500^{\circ} \mathrm{C}$ with a nitrogen purge of $40: 60 \mathrm{ml} / \mathrm{min}$ for sample: furnace respectively. TA Universal analysis software (v 4.5A, TA Instruments, Elstree, UK) was used to analyse data for both DSC and TGA.

\subsection{X-Ray Diffractometry (XRD)}

A powder X-ray diffractometer, D2 Phaser with Lynxeye (Bruker, Germany) was used to assess the physical form of the model drug and fillers within the 3D printed tablets. Samples were scanned from 2 Theta $=5^{\circ}$ to $50^{\circ}$ using $0.01^{\circ}$ step width and a $1.25 \mathrm{~s}$ time count. The divergence slit was $1 \mathrm{~mm}$ and the scatter slit $0.6 \mathrm{~mm}$. The wavelength of the X-ray was $0.154 \mathrm{~nm}$ using $\mathrm{Cu}$ source and a voltage of $30 \mathrm{kV}$. Filament emission was $10 \mathrm{~mA}$ using a scan type coupled with a theta/theta scintillation counter over $60 \mathrm{~min}$.

\subsection{Water contents}


The water content was determined using Karl Fischer method (KF) using Metorhm 870 KF Titrino plus (Metrohm UK Ltd., Runcorn, UK). Each ingredient and dried 3D printed tablets has been measured sample (500 mg) accurately weight using Mettler Toledo analytical balance (Mettler, Germany). The water content was calculated via Titrino plus software (Metrohm UK Ltd., Runcorn, UK) or end-point was utilized for $\%$ water content calculation.

\subsection{Dimensions and mechanical properties of the 3D printed tablet}

To assess the mechanical resistance of 3D printed tablets, the 3D printed tablets were assessed using Agilent 200 Tablet Hardness Tester (Agilent Technologies). Measurements of resistance to crushing of the tablet were carried out in triplicates for each selected formulation. The friability of 3D printed tablets $(n=10)$ were accurately weighed, placed in the apparatus drum of Agilent Dual-drum Friability Tester 250 (Agilent Technologies) and rotated 100 times. The dimensions of 3D tablet dimensions were assessed using eSYNic Digital Vernier digital calliper (eSYNic, China). A randomly selected 10 3D printed tablets from each selected formulation were and weighed. The average mass, standard deviation and percentage deviation from average mass were determined for each batch.

\subsection{Analysis of drug contents using HPLC}

Theophylline content of the tablets was assessed using an Agilent 1260 series UV-HPLC (Agilent Technologies, Germany) with XTerra RP 18 column $(150 \times 4.6 \mathrm{~mm}, 5 \mu \mathrm{m}$ particle size) (Waters, Ireland) as previously reported [21]. The mobile phase (86:7:7 volume ratio of $10 \mathrm{mM}$ ammonium acetate buffer: methanol: acetonitrile) was applied at flow rate of $1 \mathrm{~mL} / \mathrm{min}$ at temperature $40^{\circ} \mathrm{C}$. Samples were injected $(5 \mu \mathrm{L})$ and the run time of $7 \mathrm{~min}$ and analysis was carried out at a wavelength of $272 \mathrm{~nm}$.

\subsection{Scanning Electron Microscopy (SEM)}

The morphology and cross-section of the tablets were assessed using a JCM-6000 plus NeoScope ${ }^{\mathrm{TM}}$ microscope (Jeol, Tokyo, Japan) at $10 \mathrm{kV}$. All samples were gold coated using a JFC-1200 Fine Coater (Jeol, Tokyo, Japan). The images were collected using Image J software (v 1.2.0., Tokyo, Japan).

\subsection{In vitro disintegration and dissolution}

In vitro disintegration and drug release studies. Tablet disintegration was carried out using an Erweka ZT220 disintegration testing apparatus (Erweka GmbH, Heusenstamm, Germany). 
Three tablets were randomly selected, weighed and each placed in a basket rack assembly of six cylinders and weights were added on the top of the tablets. The basket rack assembly was then immersed into a beaker containing $0.1 \mathrm{M}$ hydrochloric acid at $37^{\circ} \mathrm{C}$. The exact time for all tablets to fully leave the mesh was visually noted.

In vitro drug release testing. The impact of the tablet's design on the release pattern of the 3D printed tablets was assessed using a USP II dissolution test paddle apparatus (Erweka GmbH, Germany). The dissolution study was conducted in $900 \mathrm{~mL}$ of $0.1 \mathrm{M}$ hydrochloric acid (pH 1.2 ) at $37 \pm 0.5^{\circ} \mathrm{C}$ and with paddle speed of $50 \mathrm{rpm}$. The amount of released theophylline was determined at 5 min intervals by UV/VIS spectrophotometer (PG Instruments Limited, UK) at a wavelength of $272 \mathrm{~nm}$ and a path length of $1 \mathrm{~mm}$. Data were analysed using IDISis software version 2012 (Automated Lab, Berkshire, UK).

\section{Results and Discussion}

The manufacturing equipment required for TASFEX is illustrated in Fig. 1. Here, a cylinder of compressed pharmaceutical ink is loaded into a metal syringe and water is added. The material is pressurised under a moderately elevated temperature $\left(50-100^{\circ} \mathrm{C}\right)$ using the support of a piston stepper motor with a built-in gear to increase the load-to-motor inertia ratio and to reduce motor oscillation. In this arrangement, the starting material can be loaded as a compressed powder in a form of cylinder (12 $\mathrm{mm}$ diameter x $60 \mathrm{~mm}$ height) to produce a set number of tablets. The simplicity of this set-up and the lack of screw parts of complicated design that necessitate special cleaning protocols make it particularly suitable for dispensing bespoke doses in a hospital setting. In the future, it is possible to employ low-cost thermally conductive disposable syringes to eliminate the risk of cross-contamination for production of multiple batches.

Initially, tablet extrusion was carried out without the inclusion of water. However, no material flow was possible at the process temperature of $90^{\circ} \mathrm{C}$. Preliminary investigations indicated that a significant increase of the plasticiser (sorbitol) ratio allow significant material flow. However, this approach led to the formation of a highly flexible matrix that was not suitable for oral tablet structure (data not shown). Here, we adapted the solution of adding water as a temporary plasticiser as previously reported [9]. In this approach, water was added to the final powder blends to facilitate the printing of these tablets. Table 1 shows the content of different formulations which were prepared using the novel TASFEX system. The inclusion of water allowed a sufficient material flow from the temperature-controlled metal syringe and 
enabled 3D printing at relatively low temperature $\left(65-100^{\circ} \mathrm{C}\right)$. The concentration of plasticiser (sorbitol) was varied in the presence of a fixed amount of water and the fabrication process was successful in a sorbitol concentration range of $15-25 \%$ w/v. A filler ratio of $20 \%$ was chosen, as it yielded the most visually desirable structure of a smooth surface and a consistent filling. In order to assess the suitability of the process to different fillers, two additional sugars (lactose and D-mannitol) were incorporated in the formulation which yielded well-structured tablets demonstrating the versatility of the process (Figs. 2 a1-d1).

SEM images indicated the formation of relatively smooth upper surface of tablets (Figs. 2 a2-d2). Each layer was composed of $300 \mu \mathrm{m}$ layers (Figs. 2 a3-d3). Interestingly, the SEM images of the cross-sections of the tablet indicated that PVA-based tablet made with lactose and D-mannitol showed individual layers, tablets that are based on PVA-sorbitol and PVPlactose demonstrated a more cohesive structure with seamless lines between the deposited layers (Figs. 2 a4-d4).

The TGA thermograph showed that all molecules were stable at the processing temperature $\left(\leq 100{ }^{\circ} \mathrm{C}\right)$ (Fig. 3). In all these examples, the 3D printed tablets appeared to lose approximately $<3 \%$ of their total mass due to moisture evaporation. The magnitude of this loss is significantly lower in the powder blend (physical mixture) in comparison to the $3 \mathrm{D}$ printed tablets, indicating that these tablets retained some level of water. To assess the impact of drying process, Karl Fisher analysis was used to assess the percentage of moisture content in the dried 3D printed tablets Table S1 (Supplementary data). The analysis indicated that drying process yielded 3D printed tablet $(\mathrm{F} 2)$ of minimal water contents $(<0.5 \%)$. While this approach offers advantages over using highly diluted drug and additive slurry [25, 27, 28] and producing relatively solid structure before any additional drying process, the elevated processing temperature might be less suitable for thermally labile drug.

DSC thermographs indicated that onset of melting points of sorbitol, lactose and mannitol of 91,140 and $164{ }^{\circ} \mathrm{C}$ respectively [37]. The physical blend indicated the presence of these peaks in their corresponding thermographs. When the 3D printed tablets were tested, minor or no endothermal peak were seen in sorbitol tablets $(n=3)$ (Fig. 4a), whilst the endotherm melting peaks was clearer in both D-mannitol and lactose thermographs (Figs. $\mathbf{4 b}$, 4c). The role of sorbitol as a plasticiser has been described before in PVA matrix [38]. The significant ability of this sugar to plasticise PVA matrix was directly related to its ability to form hydrogen bonds with -hydroxyl groups of PVA structure as well as water molecules, 
hence enhancing the polymer ability to retain water [39]. These findings suggest that lactose and mannitol might be less miscible within the PVA matrix and therefore a significant portion of the sugar were in the crystalline form within the 3D printed structure.

XRD intensity patterns indicated that sorbitol (as received) has distinctive intensity peaks of 2 Theta $=12.12^{\circ}$ and $19.1^{\mathrm{O}}$ (Fig. 5a). While these peaks appeared in the physical mixture, they were absent in the XRD patterns of the 3D printed tablets, and hence confirmed that sorbitol was mainly in the amorphous form within the 3D printed tablet matrix. However, in the case of lactose $\left(2 \mathrm{Theta}=16.4^{\circ}\right)$ and D-mannitol $\left(2\right.$ Theta $=16.9,35.9$ and $\left.44.13^{\circ}\right)$ suggesting that both fillers were in crystalline form (Figs. 5 b and c). This could be the result of applying processing temperatures $\left(90-100^{\circ} \mathrm{C}\right)$ that reached the melting point of sorbitol (91 $\left.{ }^{\circ} \mathrm{C}\right)$, but below the melting point of lactose and D-mannitol $\left(140\right.$ and $\left.164{ }^{\circ} \mathrm{C}\right)$. The presence of both lactose and D-mannitol in crystalline form might have favoured the formation of tablets of improved physical structure. XRD patterns also indicated that theophylline was in crystalline form with the presence of peaks 2 Theta $=6.8$ and $12.3^{\circ}$ (Figs. 5 a, $\mathbf{b}$ and $\mathbf{c}$ ).

The extrudability of the polymeric matrix can be linked to its rheological behaviour. The complex viscosity of the material were observed to drop down when polymer was blended with other non-melting additives [40, 41]. It was noticed that the glass transition temperature (Tg) dropped with the decrease in the complex viscosity of the mixture [41]. In another example, the addition of sugar (lactose, mannitol, or sorbitol) to polyethylene glycol matrix was noticed to help in controlling the complex viscosity [42] by maintaining a shear-thinning behaviour, which is required for extrudability followed by solidification at room temperature.

In order to demonstrate the versatility of the presented method to accommodate different polymer species, pyrrolidine derivative (PVP) was also tested as a polymer species and yielded a tablet (Fig. 2f). Physical analysis indicated that lactose was in the crystalline form (endotherm of melting peak onset at $140{ }^{\circ} \mathrm{C}$ and an intensity peak XRD patterns (2Theta $\left.=16.4^{\circ}\right)($ Fig. 6). However, when less hydrophilic polymers (e.g. Eudragit E, Eudragit L, Eudragit EPO or HPC SL) were applied in the same formulation, the solvent (water) separated from the powder bulk (Eudragit E and HPC SL) or the extruded filaments from hot nozzle failed to fuse together following application from the nozzle to yield a cohort 3D structure. This demonstrates that the reported TASFEX approach is more suitable for polymer systems with functional groups of hydrophilic properties which are able to retain water within the polymeric matrix and facilitates multilayer adhesion upon hydration. 

in Table 2. The pharmacopeial tests indicated a generally long disintegration time for 3D printed tablet structures. This is in agreement with recent reports in which polymer-rich 3D printed structures showed slow in vitro dissolution profiles despite the use of fast-dissolving polymers that are typically used for immediate release preparations [32, 43]. This in contrast to immediate release and fast disintegrating tablets are often composed with large portion of disintegrating fillers. The disintegration time was reported to be much shorter for the Dmannitol based tablet (Table 2) compared to other fillers. Such disintegrants effect of Dmannitol has been previously reported $[44,45]$.

Despite the relatively large nozzle size used for the extrusion of polymeric structure $(1.2 \mathrm{~mm})$, the majority of fabricated tablets illustrated highly reproducible dimensions and weight (Table 2). The tablets also demonstrated pharmaceutically acceptable mechanical properties of friability $(<1 \%)$. The in vitro dissolution of the fabricated tablets is shown in Fig. 7. Modifying the percentage of sorbitol in the PVA matrix appeared to have a limited impact of the rate of theophylline release (Fig. 7a). The nature of dissolution seems also to be independent of the nature of the plasticiser sugar (Fig. 7b). This indicates that the theophylline release was mainly dominated by the erosion of PVA. As the dissolution medium penetrate through PVA matrix, drug release will take place through the erosion of the hydrate matrix and diffusion through the polymeric chain networks [46]. When other PVA grades with higher and lower molecular weight were incorporated in the tablets, drug release was dependent on the molecular weight of the PVA grade (Fig. 7c). This observation can be attributed to the reduction of water diffusion co-efficient with increased molecular weight of PVA [47]. On the other hand, the use of PVP as a base for 3D printed tablets resulted in theophylline release of $>85 \%$ at $45 \mathrm{~min}$ in the gastric medium (Fig. 7d) and was compatible with the BP pharmacopeia for immediate release theophylline tablets. The fast dissolution rate from PVP matrix could be attributed to its solubility enhancing properties [48, 49]. Drug release from 3D printed tablets seemed to mimic that from tablets produced via FDM 3D printing [21, 24, 50]. Upon introduction to aqueous media, the polymer-rich structure of these tablets resulted in formation of gel-like layer [51]. Further acceleration to drug release could be achieved through design approach [43].

Despite the significant advances of the reported approach, it is confined to small batch manufacturing and is less suitable for large scale or continuous manufacturing. Although drying time is relatively brief, the combination of heat and water might accelerate drug 
degradation particularly if hydrolysis-labile molecule is incorporated. The omittance of the drying process could be achieved by avoiding the use of solvent, however, this will involve use of high processing temperature or materials of low melting points. This highlights the importance of carefully selecting the 3D printing manufacturing approach to suit a particular active molecule and batch size.

\section{Conclusion}

We have reported a novel hybrid approach of combined temperature and solvent (water) to facilitate the additive manufacturing of immediate release tablets using simple extrusion. The proposed process was compatible with pharmaceutical grade hygroscopic polymers (PVA and PVP). We demonstrated that the starting material was compatible with a number of fillers (lactose, sorbitol and D-mannitol). The produced tablets demonstrated pharmacopeial acceptable weight and content uniformity and proved mechanically resistant. This reported hybrid approach offers significant advantages compared to other 3DP technologies: i) replacing difficult-to-engineer FDM -compatible filament with a simpler powder or compact cylinder, ii) the use of a moderate temperature range $\left(65-100^{\circ} \mathrm{C}\right)$, iii) a brief drying period, and iv) avoiding the use of mechanically complicated and hard-to-clean direct extruder machinery. These novel features can provide hospital and compounding units with a simple, low-cost approach to dispense small batch of patient-customised tablets. However, for continuous manufacturing, removal of drying step, and hydrolysis labile drugs, other manufacturing approach could be considered. 
Fig. 1. Equipment for TASFEX 3D printing. (a) The printer is equipped with a metal syringe surrounded by temperature-controlled heating jacket. The syringe is fitted with a luer-lock stainless steel needle, (b) The pharmaceutical ink (compressed powder) is added. The ink is then extruded by a piston pushed by computer-controlled stepper motor equipped with gear to produce (c) 3D printed tablet.

Fig. 2 Photographs of 3D printed tablets based on (a1) PVA and sorbitol, (b1) PVA and lactose and (c1) PVA and D-mannitol and (d1) PVP and lactose. SEM images of (a2, b2, c2 and d2) top view, (a3, b3, c3 and d3) side view, and (a4, b4, c4 and d42) cross sections of these tablets.

Fig. 3 TGA thermal degradation profiles of raw theophylline, PVA, Sodium stearyl fumarate (PRUV), filler [ (a) sorbitol, (b) lactose and (c) D-mannitol], pharmaceutical ink (prior to addition of water) and $3 \mathrm{D}$ printed tablets.

339 Fig. 4 DSC thermograph of raw theophylline, PVA, Sodium stearyl fumarate (PRUV), filler [(a) 340 sorbitol, (b) lactose and (c) D-mannitol], pharmaceutical ink (prior to addition of water) and 3D printed 341 tablets.

342 Fig. 5 XRD patterns of raw theophylline, PVA, Sodium stearyl fumarate (PRUV), filler [ (a) sorbitol, 343 (b) lactose and (c) D-mannitol, pharmaceutical ink (prior to addition of water) and 3D printed tablets.

344 Fig. 63 D Printed tablet based on poly(vinylpyridine) (PVP) (A) TGA thermal degradation profiles, (B) 345 DSC thermograph profiles, (C) XRD patterns of raw theophylline, PVP, Sodium stearyl fumarate (PRUV), lactose, pharmaceutical ink (prior to addition of water) and 3D printed tablets.

347 Fig. 7 Impact of (a) sorbitol percentage, (b) nature of filler (sorbitol, lactose and D-mannitol), and (c) 348 molecular weight of PVA on the in vitro dissolution of theophylline from 3D printed tablets, (d) in vitro 349 dissolution of theophylline from 3D printed PVP based tablets $(n=3, \pm S D)$.

\section{$350 \quad$ List of tables}

351 Table 1 Composition of materials used in TASFEX, extrusion and plate temperatures

352 Table 2 Diameter, height, weight uniformity, friability, hardness, disintegration and drug content.

\section{Supplementary Data}

Table S1 Water content of ingredients, physical mixture, freshly prepared and dried 3D printed tablet 
[1] W. Burke, H. Burton, A.E. Hall, M. Karmali, M.J. Khoury, B. Knoppers, E.M. Meslin, F. Stanley, C.F. the agenda for public health in an era of genome-based and "personalized" medicine?, Genet Med, 12 (2010) 785-791.

[2] A. Alyass, M. Turcotte, D. Meyre, From big data analysis to personalized medicine for all: challenges and opportunities, BMC Med Genomics, 8 (2015) 33.

[3] J. Savard, Personalised medicine: a critique on the future of health care, J Bioeth Inq, 10 (2013) 197-203.

[4] M.A. Alhnan, T.C. Okwuosa, M. Sadia, K.W. Wan, W. Ahmed, B. Arafat, Emergence of 3D Printed Dosage Forms: Opportunities and Challenges, Pharm Res, 33 (2016) 1817-1832.

[5] A. Awad, S.J. Trenfield, S. Gaisford, A.W. Basit, 3D printed medicines: A new branch of digital healthcare, Int J Pharm, 548 (2018) 586-596.

[6] H. Oblom, E. Sjoholm, M. Rautamo, N. Sandler, Towards Printed Pediatric Medicines in Hospital Pharmacies: Comparison of 2D and 3D-Printed Orodispersible Warfarin Films with Conventional Oral Powders in Unit Dose Sachets, Pharmaceutics, 11 (2019).

[7] N. Scoutaris, S.A. Ross, D. Douroumis, 3D Printed "Starmix" Drug Loaded Dosage Forms for Paediatric Applications, Pharm Res, 35 (2018) 34.

[8] P. Robles-Martinez, X. Xu, S.J. Trenfield, A. Awad, A. Goyanes, R. Telford, A.W. Basit, S. Gaisford, 3D Printing of a Multi-Layered Polypill Containing Six Drugs Using a Novel Stereolithographic Method, Pharmaceutics, 11 (2019).

[9] B.C. Pereira, A. Isreb, R.T. Forbes, F. Dores, R. Habashy, J.B. Petit, M.A. Alhnan, E.F. Oga, 'Temporary Plasticiser': A novel solution to fabricate 3D printed patient-centred cardiovascular 'Polypill' architectures, European journal of pharmaceutics and biopharmaceutics : official journal of Arbeitsgemeinschaft fur Pharmazeutische Verfahrenstechnik e.V, 135 (2019) 94-103.

[10] S.A. Khaled, J.C. Burley, M.R. Alexander, J. Yang, C.J. Roberts, 3D printing of five-in-one dose combination polypill with defined immediate and sustained release profiles, Journal of controlled release : official journal of the Controlled Release Society, 217 (2015) 308-314.

[11] A. Ajmal, A. Meskarzadeh, N. Genina, C. Hirschberg, J.P. Boetker, J. Rantanen, The Use of 3D Printed Molds to Cast Tablets with a Designed Disintegration Profile, AAPS PharmSciTech, 20 (2019) 127.

[12] A. Goyanes, A.B. Buanz, A.W. Basit, S. Gaisford, Fused-filament 3D printing (3DP) for fabrication of tablets, Int J Pharm, 476 (2014) 88-92.

[13] H.E. Gultekin, S. Tort, F. Acarturk, An Effective Technology for the Development of Immediate Release Solid Dosage Forms Containing Low-Dose Drug: Fused Deposition Modeling 3D Printing, Pharm Res, 36 (2019) 128.

[14] Q. Li, H. Wen, D. Jia, X. Guan, H. Pan, Y. Yang, S. Yu, Z. Zhu, R. Xiang, W. Pan, Preparation and investigation of controlled-release glipizide novel oral device with three-dimensional printing, Int J Pharm, 525 (2017) 5-11.

[15] M. Saviano, R.P. Aquino, P. Del Gaudio, F. Sansone, P. Russo, Poly(vinyl alcohol) 3D printed tablets: The effect of polymer particle size on drug loading and process efficiency, Int J Pharm, 561 (2019) 1-8.

[16] J. Skowyra, K. Pietrzak, M.A. Alhnan, Fabrication of extended-release patient-tailored prednisolone tablets via fused deposition modelling (FDM) 3D printing, European journal of pharmaceutical sciences : official journal of the European Federation for Pharmaceutical Sciences, 68 (2015) 11-17.

[17] A. Goyanes, A.B. Buanz, G.B. Hatton, S. Gaisford, A.W. Basit, 3D printing of modified-release aminosalicylate (4-ASA and 5-ASA) tablets, European journal of pharmaceutics and biopharmaceutics : official journal of Arbeitsgemeinschaft fur Pharmazeutische Verfahrenstechnik e.V, 89 (2015) 157162. 
[18] J. Aho, J.P. Botker, N. Genina, M. Edinger, L. Arnfast, J. Rantanen, Roadmap to 3D-Printed Oral Pharmaceutical Dosage Forms: Feedstock Filament Properties and Characterization for Fused Deposition Modeling, J Pharm Sci, 108 (2019) 26-35.

[19] E. Fuenmayor, M. Forde, A.V. Healy, D.M. Devine, J.G. Lyons, C. McConville, I. Major, Material Considerations for Fused-Filament Fabrication of Solid Dosage Forms, Pharmaceutics, 10 (2018). [20] J.M. Nasereddin, N. Wellner, M. Alhijjaj, P. Belton, S. Qi, Development of a Simple Mechanical Screening Method for Predicting the Feedability of a Pharmaceutical FDM 3D Printing Filament, Pharm Res, 35 (2018) 151.

[21] T.C. Okwuosa, D. Stefaniak, B. Arafat, A. Isreb, K.W. Wan, M.A. Alhnan, A Lower Temperature FDM 3D Printing for the Manufacture of Patient-Specific Immediate Release Tablets, Pharm Res, 33 (2016) 2704-2712.

[22] G. Kollamaram, D.M. Croker, G.M. Walker, A. Goyanes, A.W. Basit, S. Gaisford, Low temperature fused deposition modeling (FDM) 3D printing of thermolabile drugs, Int J Pharm, 545 (2018) 144152.

[23] W. Kempin, V. Domsta, I. Brecht, B. Semmling, S. Tillmann, W. Weitschies, A. Seidlitz, Development of a dual extrusion printing technique for an acid- and thermo-labile drug, European journal of pharmaceutical sciences : official journal of the European Federation for Pharmaceutical Sciences, 123 (2018) 191-198.

[24] W. Kempin, V. Domsta, G. Grathoff, I. Brecht, B. Semmling, S. Tillmann, W. Weitschies, A. Seidlitz, Immediate Release 3D-Printed Tablets Produced Via Fused Deposition Modeling of a Thermo-Sensitive Drug, Pharm Res, 35 (2018) 124.

[25] S.A. Khaled, M.R. Alexander, D.J. Irvine, R.D. Wildman, M.J. Wallace, S. Sharpe, J. Yoo, C.J. Roberts, Extrusion 3D Printing of Paracetamol Tablets from a Single Formulation with Tunable Release Profiles Through Control of Tablet Geometry, AAPS PharmSciTech, 19 (2018) 3403-3413. [26] S.A. Khaled, M.R. Alexander, R.D. Wildman, M.J. Wallace, S. Sharpe, J. Yoo, C.J. Roberts, 3D extrusion printing of high drug loading immediate release paracetamol tablets, Int J Pharm, 538 (2018) 223-230.

[27] I.E. Aita, J. Breitkreutz, J. Quodbach, Investigation of semi-solid formulations for 3D printing of drugs after prolonged storage to mimic real-life applications, Eur J Pharm Sci, 146 (2020) 105266. [28] Q. Li, X. Guan, M. Cui, Z. Zhu, K. Chen, H. Wen, D. Jia, J. Hou, W. Xu, X. Yang, W. Pan, Preparation and investigation of novel gastro-floating tablets with 3D extrusion-based printing, Int J Pharm, 535 (2018) 325-332.

[29] Z. Zheng, J. Lv, W. Yang, X. Pi, W. Lin, Z. Lin, W. Zhang, J. Pang, Y. Zeng, Z. Lv, H. Lao, Y. Chen, F. Yang, Preparation and application of subdivided tablets using 3D printing for precise hospital dispensing, Eur J Pharm Sci, 149 (2020) 105293.

[30] K. Vithani, A. Goyanes, V. Jannin, A.W. Basit, S. Gaisford, B.J. Boyd, A Proof of Concept for 3D Printing of Solid Lipid-Based Formulations of Poorly Water-Soluble Drugs to Control Formulation Dispersion Kinetics, Pharm Res, 36 (2019) 102.

[31] A. Goyanes, C.M. Madla, A. Umerji, G. Duran Pineiro, J.M. Giraldez Montero, M.J. Lamas Diaz, M. Gonzalez Barcia, F. Taherali, P. Sanchez-Pintos, M.L. Couce, S. Gaisford, A.W. Basit, Automated therapy preparation of isoleucine formulations using 3D printing for the treatment of MSUD: First single-centre, prospective, crossover study in patients, Int J Pharm, 567 (2019) 118497. [32] A. Goyanes, N. Allahham, S.J. Trenfield, E. Stoyanov, S. Gaisford, A.W. Basit, Direct powder extrusion 3D printing: Fabrication of drug products using a novel single-step process, Int J Pharm, 567 (2019) 118471.

[33] W. Grymonpre, W. De Jaeghere, E. Peeters, P. Adriaensens, J.P. Remon, C. Vervaet, The impact of hot-melt extrusion on the tableting behaviour of polyvinyl alcohol, Int J Pharm, 498 (2016) 254262. [34] Merck, Parteck MXP: Technical Informatiol, in, 2016. 
[35] H.L. Ohrem, E. Schornick, A. Kalivoda, R. Ognibene, Why is mannitol becoming more and more popular as a pharmaceutical excipient in solid dosage forms?, Pharm Dev Technol, 19 (2014) 257262.

[36] J. Quodbach, P. Kleinebudde, A critical review on tablet disintegration, Pharm Dev Technol, 21 (2016) 763-774. [37] P. Mura, M.T. Faucci, A. Manderioli, S. Furlanetto, S. Pinzauti, Thermal analysis as a screening technique in preformulation studies of picotamide solid dosage forms, Drug Dev Ind Pharm, 24 (1998) 747-756.

[38] M. Mohsin, A. Hossin, Y. Haik, Thermomechanical properties of poly(vinyl alcohol) plasticized with varying ratios of sorbitol, Mat Sci Eng a-Struct, 528 (2011) 925-930. [39] H.F. Tian, D. Liu, Y.Y. Yao, S.B. Ma, X. Zhang, A.M. Xiang, Effect of Sorbitol Plasticizer on the Structure and Properties of Melt Processed Polyvinyl Alcohol Films, J Food Sci, 82 (2017) 2926-2932. [40] A. Isreb, K. Baj, M. Wojsz, M. Isreb, M. Peak, M.A. Alhnan, 3D printed oral theophylline doses with innovative 'radiator-like' design: Impact of polyethylene oxide (PEO) molecular weight, Int J Pharm, 564 (2019) 98-105.

[41] M. Sadia, A. Sosnicka, B. Arafat, A. Isreb, W. Ahmed, A. Kelarakis, M.A. Alhnan, Adaptation of pharmaceutical excipients to FDM 3D printing for the fabrication of patient-tailored immediate release tablets, Int J Pharm, 513 (2016) 659-668.

[42] B.C. Pereira, A. Isreb, M. Isreb, E.F. Forbes, E.F. Oga, M.A. Alhnan, Additive manufacturing of a point-of-care "polypill": Fabrication of concept capsules of complex geometry with bespoke release against cardiovascular disease Advanced Healthcare Materials, (Accepted) (2020).

[43] M. Sadia, B. Arafat, W. Ahmed, R.T. Forbes, M.A. Alhnan, Channelled tablets: An innovative approach to accelerating drug release from 3D printed tablets, J Control Release, 269 (2018) 355363.

[44] J.S. Wilkhu, S.E. McNeil, D.E. Anderson, M. Kirchmeier, Y. Perrie, Development of a solid dosage platform for the oral delivery of bilayer vesicles, European journal of pharmaceutical sciences : official journal of the European Federation for Pharmaceutical Sciences, 108 (2017) 71-77.

[45] A.H. Ibrahim, E. Rosqvist, J.H. Smatt, H.M. Ibrahim, H.R. Ismael, M.I. Afouna, A.M. Samy, J.M. Rosenholm, Formulation and optimization of lyophilized nanosuspension tablets to improve the physicochemical properties and provide immediate release of silymarin, International Journal of Pharmaceutics, 563 (2019) 217-227.

[46] G.A. Gonzalez Novoa, J. Heinamaki, S. Mirza, O. Antikainen, A.I. Colarte, A.S. Paz, J. Yliruusi, Physical solid-state properties and dissolution of sustained-release matrices of polyvinylacetate, Eur J Pharm Biopharm, 59 (2005) 343-350.

[47] J.E.M. Snaar, R. Bowtell, C.D. Melia, S. Morgan, B. Narasimhan, N.A. Peppas, Self-diffusion and molecular mobility in PVA-based dissolution-controlled systems for drug delivery, Magnetic Resonance Imaging, 16 (1998) 691-694.

[48] E. Karavas, E. Georgarakis, M.P. Sigalas, K. Avgoustakis, D. Bikiaris, Investigation of the release mechanism of a sparingly water-soluble drug from solid dispersions in hydrophilic carriers based on physical state of drug, particle size distribution and drug-polymer interactions, Eur J Pharm Biopharm, 66 (2007) 334-347.

[49] F.I. Kanaze, E. Kokkalou, I. Niopas, M. Georgarakis, A. Stergiou, D. Bikiaris, Dissolution enhancement of flavonoids by solid dispersion in PVP and PEG matrixes: A comparative study, J Appl Polym Sci, 102 (2006) 460-471.

[50] T.C. Okwuosa, B.C. Pereira, B. Arafat, M. Cieszynska, A. Isreb, M.A. Alhnan, Fabricating a ShellCore Delayed Release Tablet Using Dual FDM 3D Printing for Patient-Centred Therapy, Pharm Res, 34 (2017) 427-437.

[51] B. Arafat, M. Wojsz, A. Isreb, R.T. Forbes, M. Isreb, W. Ahmed, T. Arafat, M.A. Alhnan, Tablet fragmentation without a disintegrant: A novel design approach for accelerating disintegration and drug release from 3D printed cellulosic tablets, Eur J Pharm Sci, 118 (2018) 191-199. 


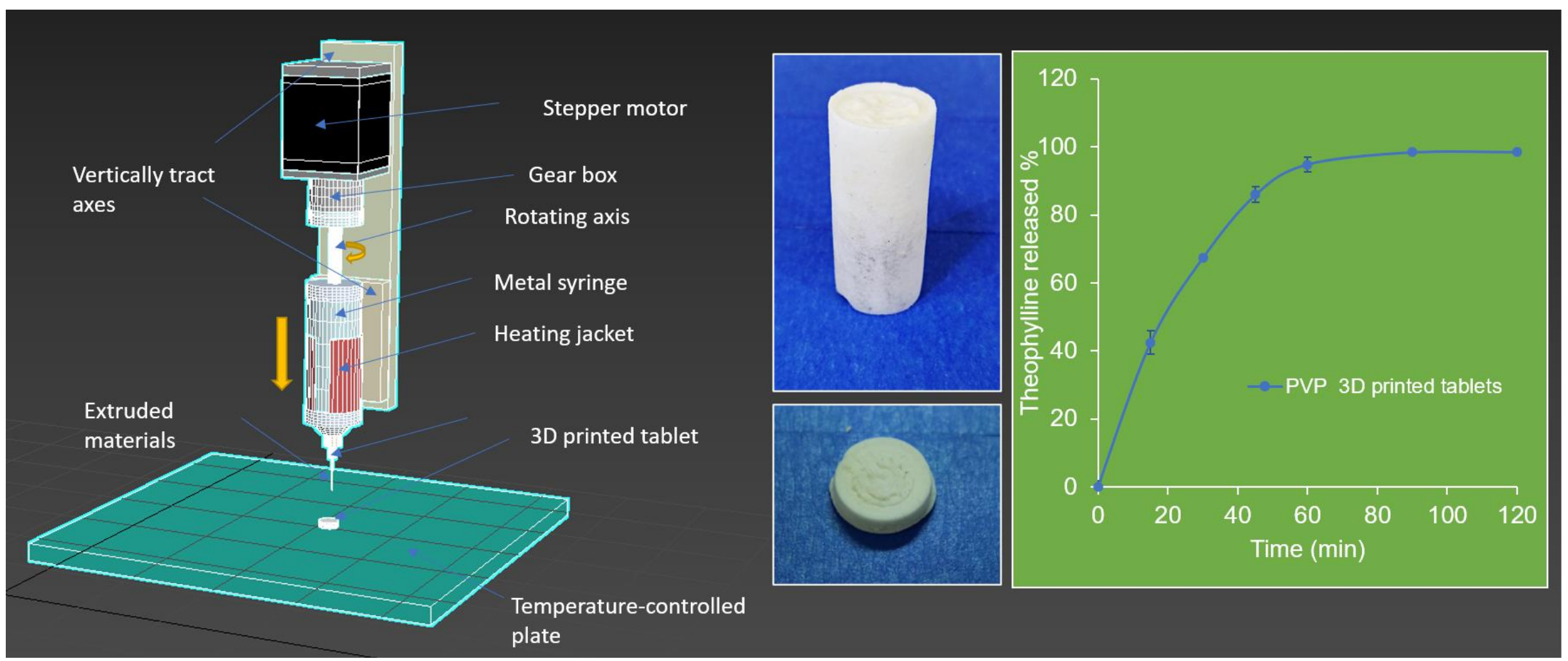

Fig. 1. Equipment for TASFEX 3D printing. (a) The printer is equipped with a metal syringe surrounded by temperature-controlled heating jacket. The syringe is fitted with a luer-lock stainless steel needle, (b) The pharmaceutical ink (compressed powder) is added. The ink is then extruded by a piston pushed by computer-controlled stepper motor equipped with gear to produce (c) 3D printed tablet. 

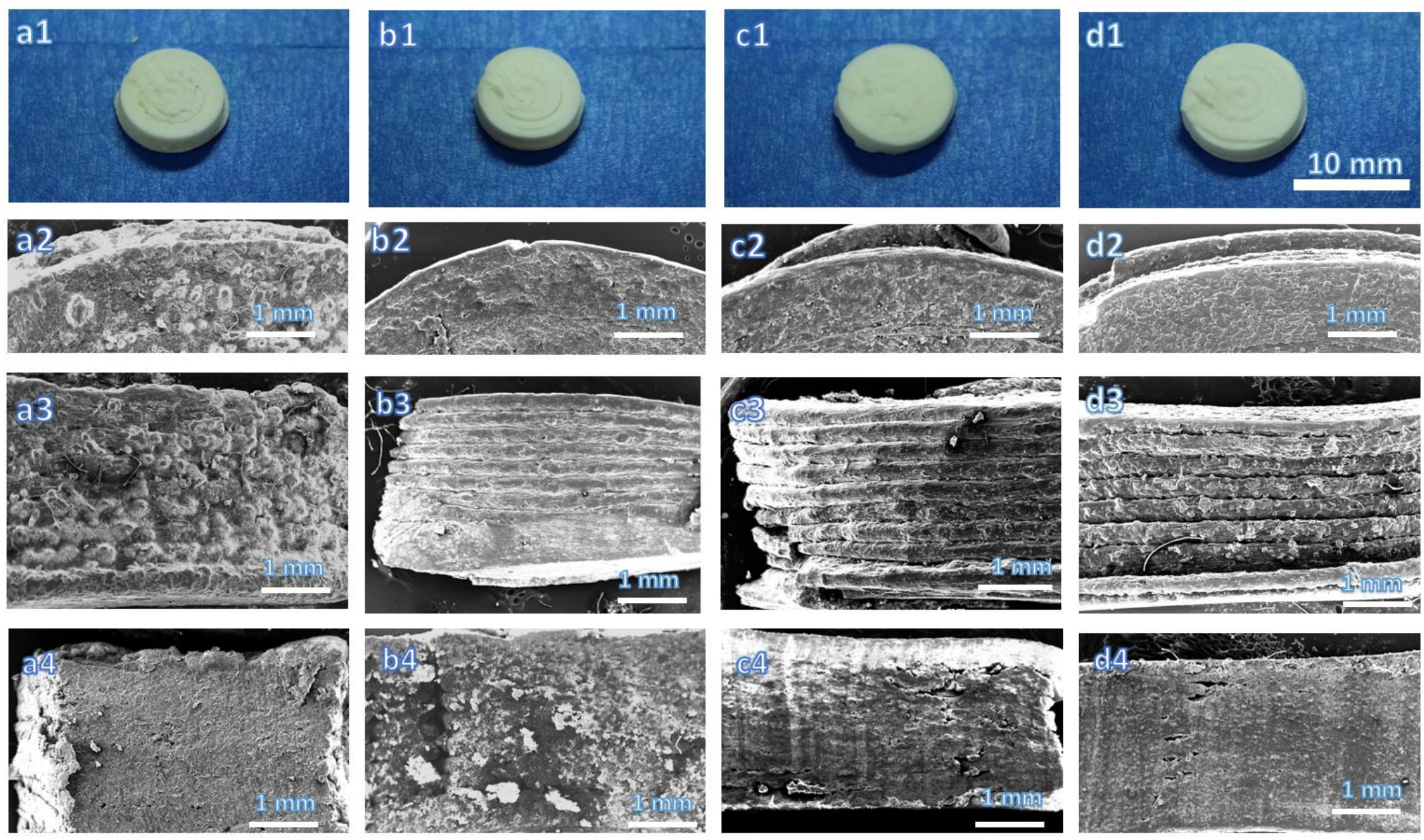

Fig. 2 Photographs of 3D printed tablets based on (a1) PVA and sorbitol, (b1) PVA and lactose and (c1) PVA and D-mannitol and (d1) PVP and lactose. SEM images of (a2, b2, c2 and d2) top view, (a3, b3, c3 and d3) side view, and (a4, b4, c4 and d42) cross sections of these tablets. 

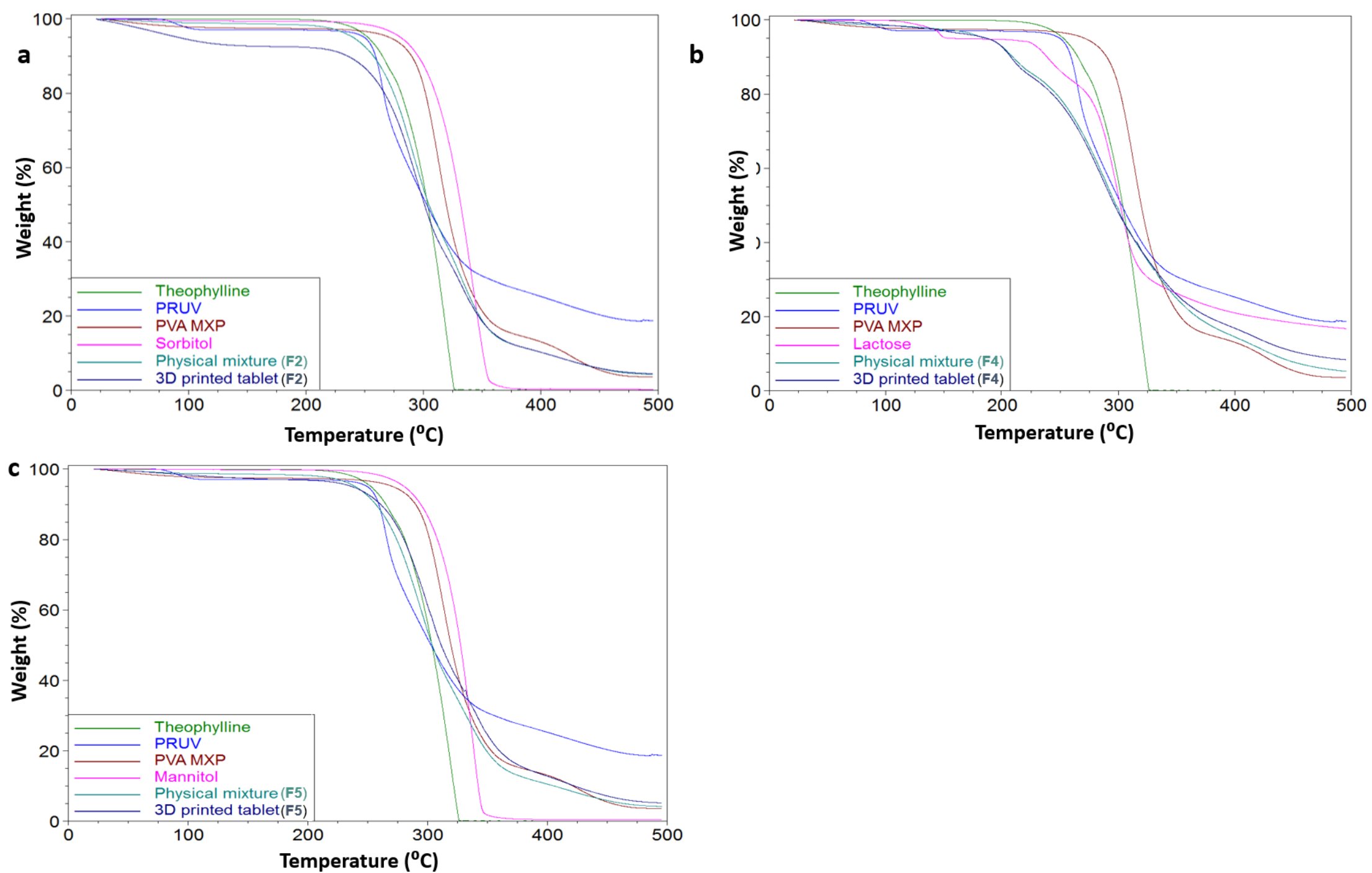

516 Fig. 3 TGA thermal degradation profiles of raw theophylline, PVA, Sodium stearyl fumarate (PRUV), filler [ (a) sorbitol, (b) lactose and (c) D-mannitol], 517 pharmaceutical ink (prior to addition of water) and 3D printed tablets. 

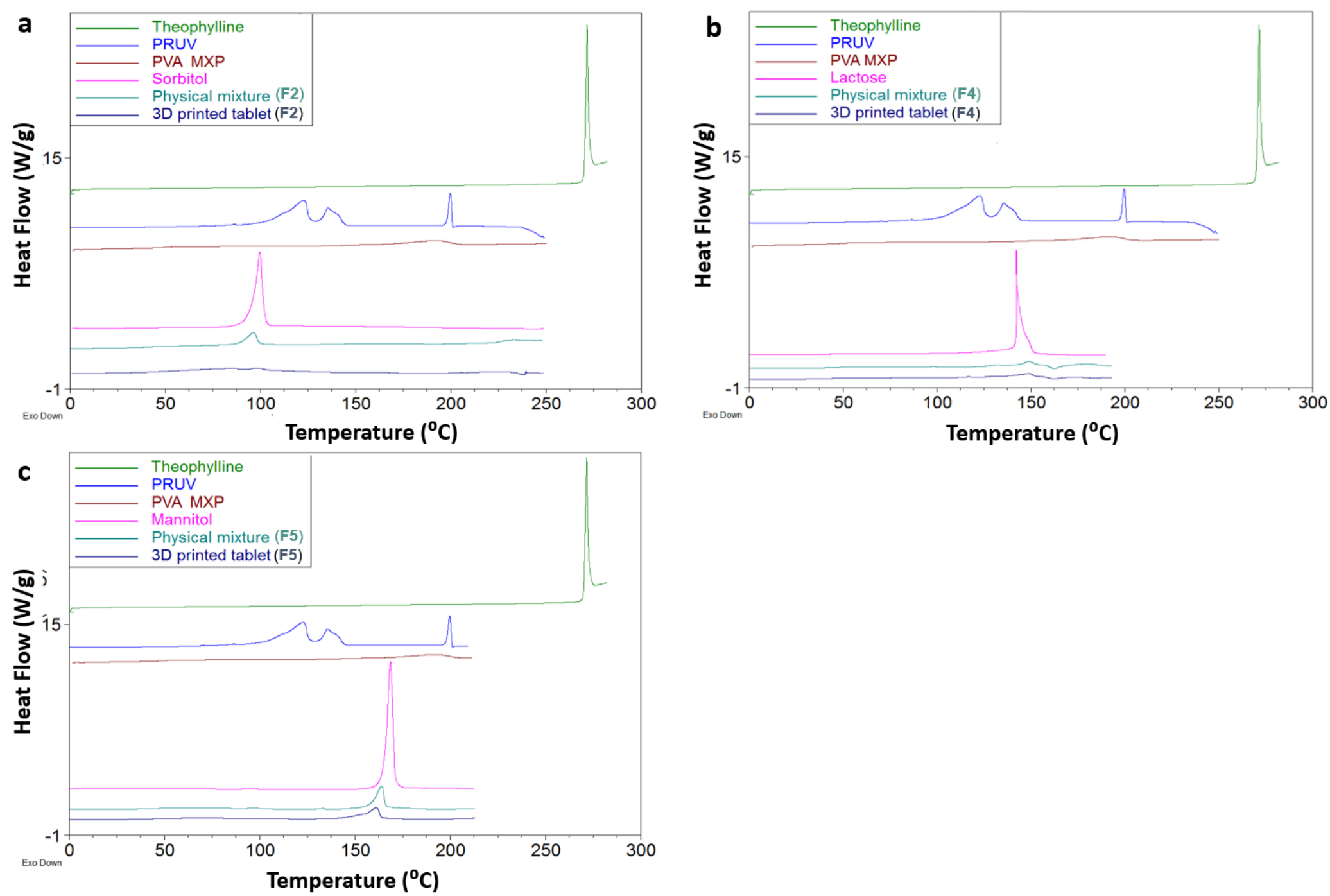

519 Fig. 4 DSC thermograph of raw theophylline, PVA, Sodium stearyl fumarate (PRUV), filler [(a) sorbitol, (b) lactose and (c) D-mannitol], pharmaceutical ink 520 (prior to addition of water) and 3D printed tablets. 
a

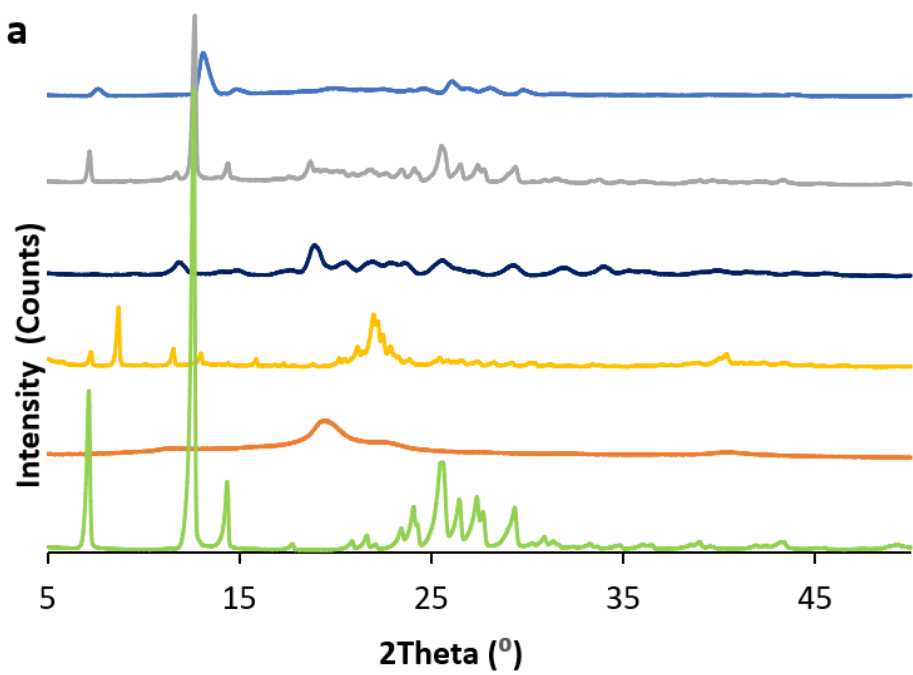

C

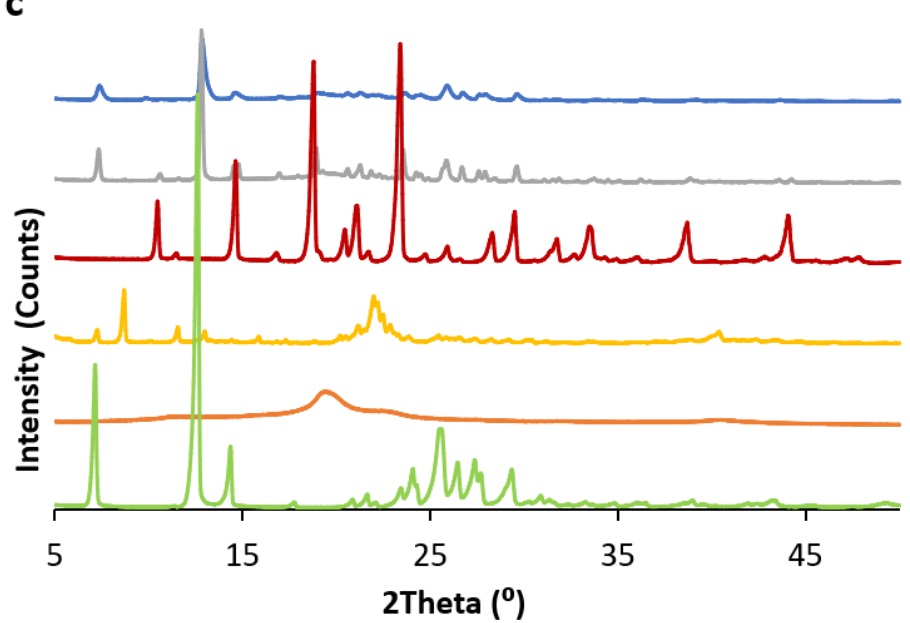

b

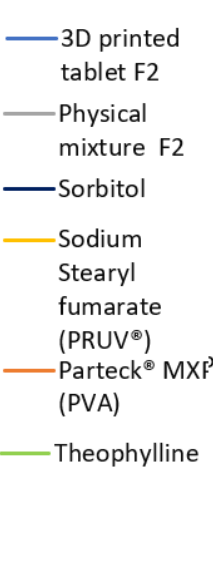

-3D printed tablet F5

- Physical mixture

F5

-Mannitol

— Sodium Stearyl

fumarate

(PRUV ${ }^{\circledR}$ )

- Parteck ${ }^{\circledR}$ MXP

(PVA)

-Theophylline

Fig. 5 XRD patterns of raw theophylline, PVA, Sodium stearyl fumarate (PRUV), filler [ (a) sorbitol, (b) lactose and (c) D-mannitol, pharmaceutical ink (prior

to addition of water) and $3 \mathrm{D}$ printed tablets. 
a
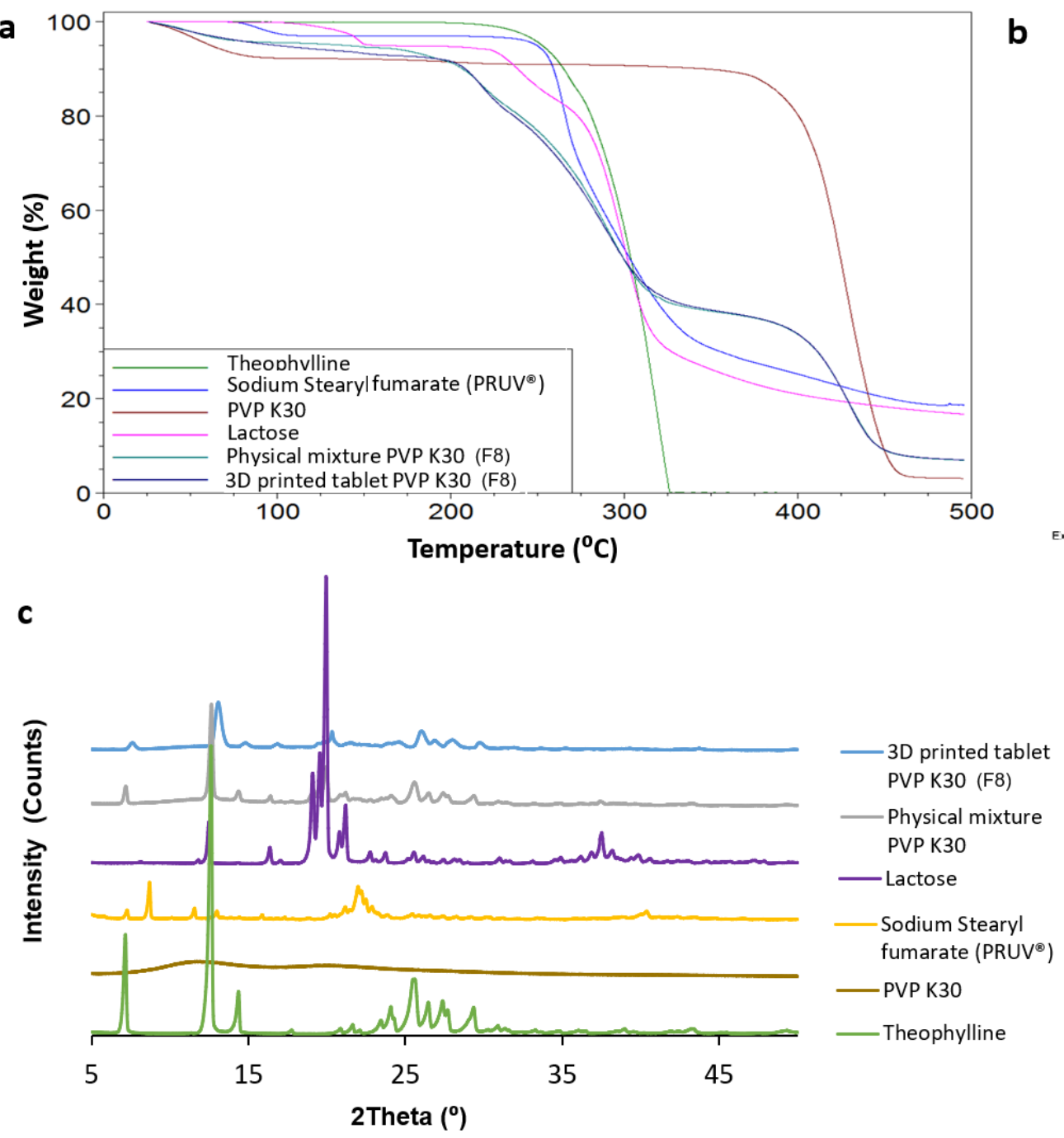

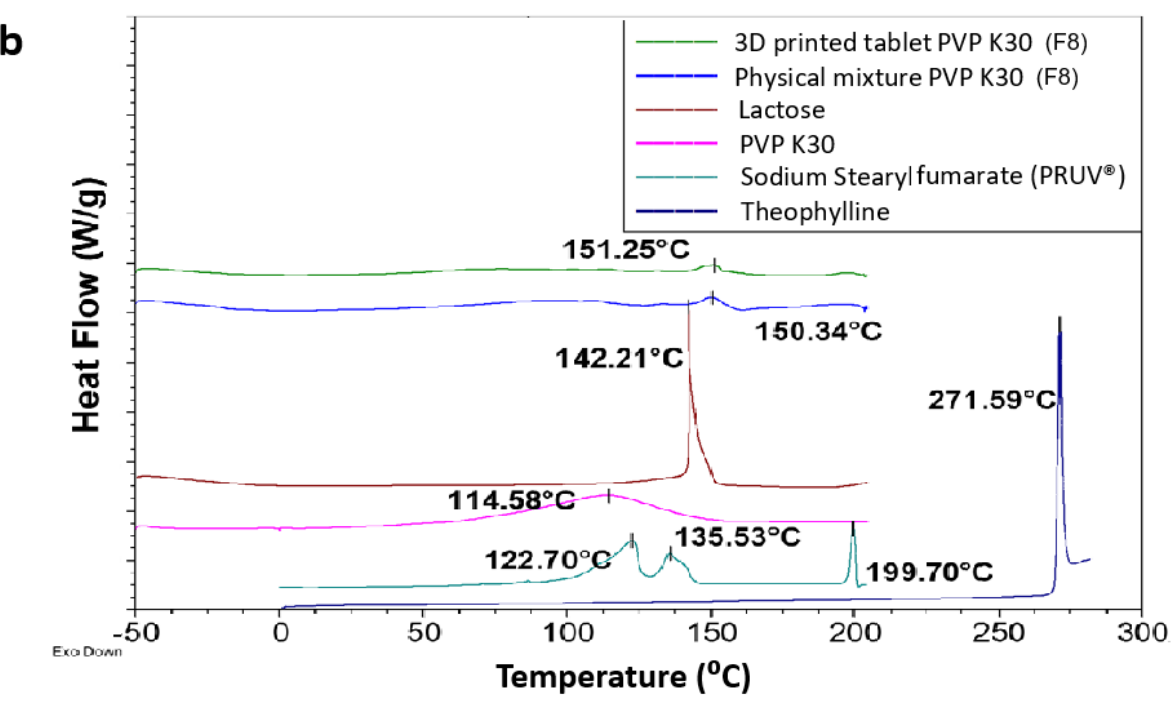

Fig. 6 3D Printed tablet based on poly(vinylpyridine) (PVP) (A) TGA thermal degradation profiles, (B) DSC thermograph profiles, (C) XRD patterns of raw theophylline, PVP, Sodium stearyl fumarate (PRUV), lactose, pharmaceutical ink (prior to addition of water) and 3D printed tablets. 

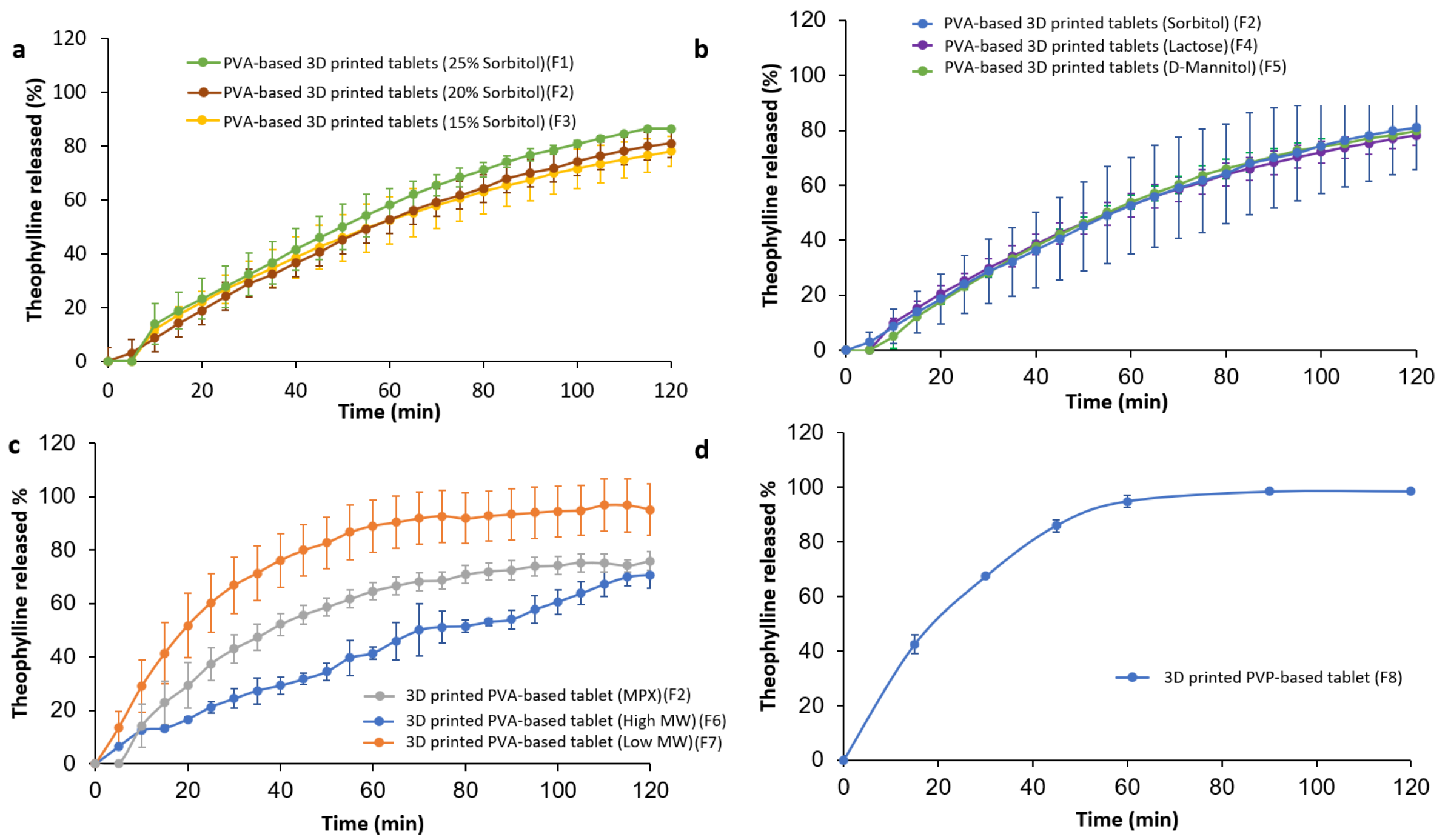

Fig. 7 Impact of (a) sorbitol percentage, (b) nature of filler (sorbitol, lactose and D-mannitol), and (c) molecular weight of PVA on the in vitro dissolution of theophylline from 3D printed tablets, (d) in vitro dissolution of theophylline from $3 \mathrm{D}$ printed PVP based tablets $(\mathrm{n}=3, \pm \mathrm{SD})$. 